\title{
Evolution of the Human Life Cycle
}

BARRY BOGIN ${ }^{1}$ AND B. HOLLY SMITH ${ }^{2}$
'Department of Behavioral Sciences, Universily of Michigan-Dearborn,
Dearborn, Michigan 48128, 'Museum of Anlhropology, University of
Michigan, Ann Arbor, Michigan 48709

\begin{abstract}
Social mammals have three basic stages of postnatal development: infant, juvenile, and adult. Some species also have a brief female postreproductive stage. The human life cycle, however, is best described by five stages: infant, child, juvenile, adolescent, and adult. Women in both traditional and industrial societies may also have a long post-reproductive stage. Analyses of bones and teeth of early hominids who died as subadults suggest that the evolution of the new life stages of childhood and adolescence are not of ancient origin. The current human pattern evolved after the appearance of Homo erectus. It is possible that evidence for the existence of the postreproductive stage for women will also be recoverable from the fossil record because the hormonal changes associated with menopause have profound effects on bone density and histology of tubular bones. It is hypothesized that the new life stages of the human life cycle represent feeding and reproductive specializations of the genus Homo. 1996 Wiley-Liss, Inc.
\end{abstract}

Anthropologists have become increasingly interested in explaining the significance of life cycle characteristics of the human species. This is because the human life cycle (also referred to as "life history") stands in sharp contrast to other species of social mammals, even other primates. Theory needs to explains how humans successfully combined a vastly extended period of offspring dependency and delayed reproduction with helpless newborns, a short duration of breast-feeding, an adolescent growth spurt, and menopause. Are these characteristics a package or a mosaic?

\section{LIFE HISTORY AND STAGES OF THE LIFE CYCLE}

"A broad definition of life history includes not only the traditional foci such as age-related fecundity and mortality rates, but also the entire sequence of behavorial, physiological, and morphological changes that an organism passes through during its development from conception to death" (Shea, 1990, p. 325). Recent work in mammalian life history and its evolution focuses on the postnatal to adulthood period of the life cycle. One way to define the stages of the life cycle is by biological characteristics. Changes in the rate of growth and the onset of sexual matu- ration (puberty) are two such characteristics. The majority of mammals progress from infancy to adulthood seamlessly, without any intervening stages, and puberty occurs while growth rates are in decline (Bertalanffy, 1960). This pattern of postnatal growth is illustrated in Figure 1 using data for the mouse. Highly social mammals, such as wolves, wild dogs, lions, elephants, and the primates (e.g., the baboon, Fig. 2), postpone puberty by inserting a period of juvenile growth and behavior betwcen infancy and adulthood. In these animals, puberty occurs while the rate of growth is still decelerating.

The pattern of human growth after birth may be characterized by five stages: infancy, childhood, juvenile, adolescence, and adulthood (Bogin, 1988, 1990, 1993). Changes in growth rate are associated with each stage as shown in Figure 3. Changes in trophic and reproductive behavior are also associated with each stage. As for all mammals, human infancy is the period when the mother provides all or some nourishment to her offspring via lactation. Human infancy

Received November 21, 1994; accepted April 15, 1990 .

Address reprint requests to Barry Bogin, Dept. of Behavioral Sciences, University of Michigan-Dearborn, Dearborn, MI 48128. 


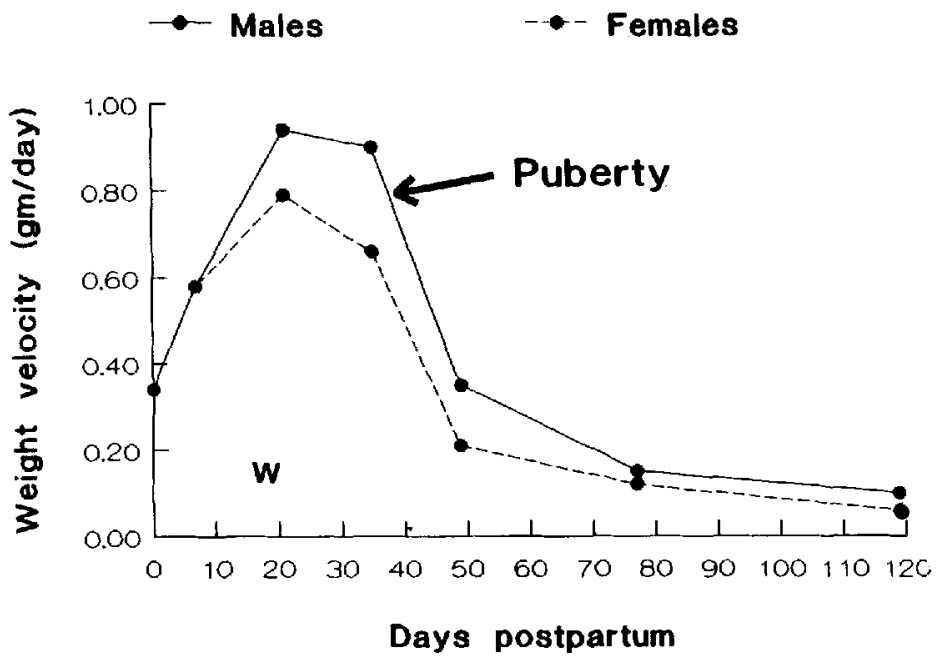

Fig. 1. Velocity curves for weight growth in the mouse. In both sexes puberty (vaginal opening for females or spermatocytes in testes of males) oceurs just after weaning and maximal growth rate. Weaning (W) takes place between days 15 and 20 . (Reproduced from Tanner, 1962, with permission of the publisher.)

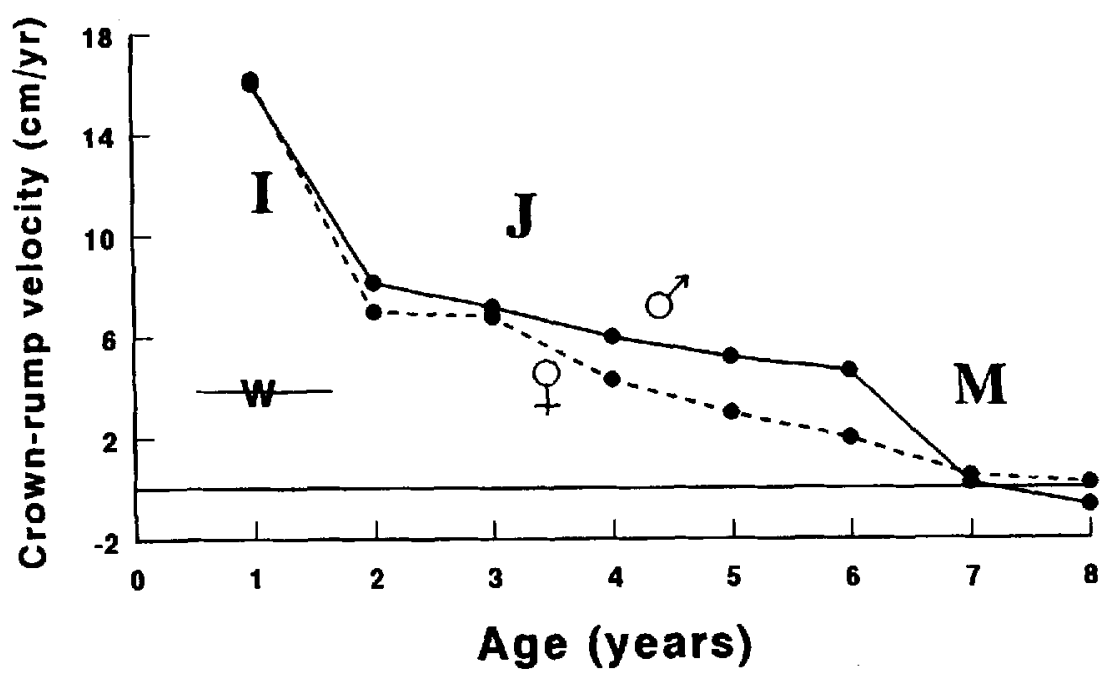

Fig. 2. Baboon crown-rump length velocity. The letters indicate the stages of growth: I, infancy; J juvenile; $M$, sexual maturity. In the wild the weaning (W) process begins as early as 4 months of age and ends by 12-18 months (Altmann, 1980). Puberty begins at about 3.5 years in females ( $O$ ) and 4.5 years in males $(\delta)$ and ends by about 6.0 years in both sexes. Redrawn with some data smoothing from Coelho (1985). The pattern of growth for other primate species, including chimpanzees, is similar to that for the baboon (see Bogin, 1988, pp. 57-68). 


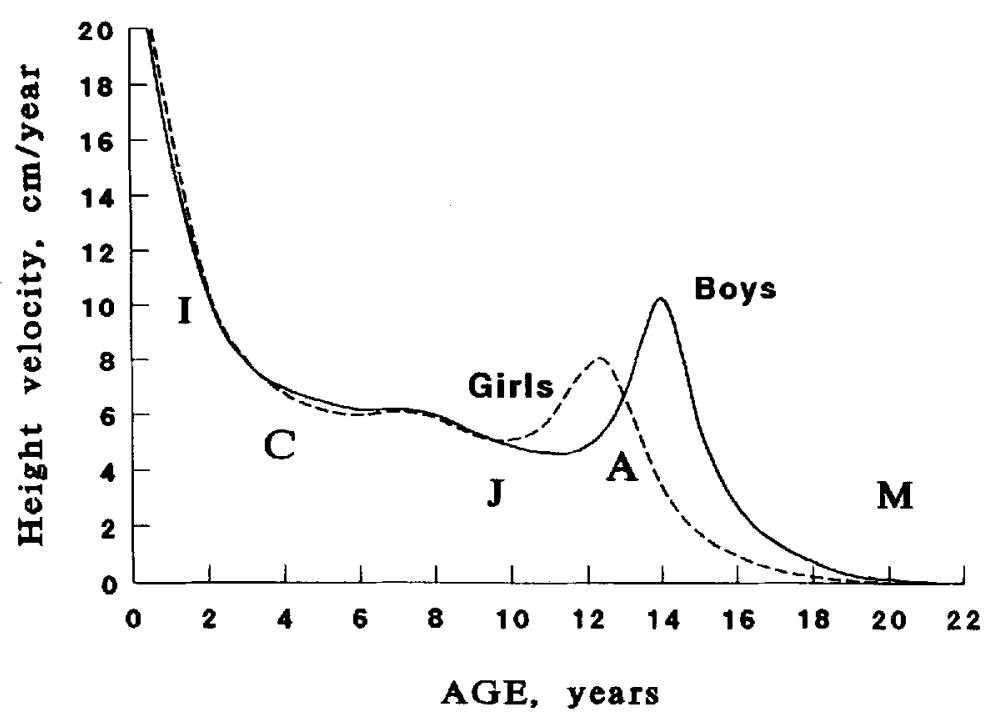

Fig. 3. Idcalized mean velocity curves of growth in height for healthy girls and boys. I, infancy; C, childhood; J, juvenile; A, adolescence; M, mature adult. (After Prader, 1984, and other sources.)

ends when the child is weaned from the brcast, which in preindustrialized societies occurs at a median age of 36 months (Dettwyler, 1994). Childhood is defined as the period following weaning, when the youngster still depends on older people for feeding and protection. Children require specially prepared foods due to the immaturity of their dentition and digestive tracts, and rapid growth of their brain (Fig. 4). These constraints necessitate a diet low in total volume but dense in energy, lipids, and proteins. Children are also especially vulnerable to predation and disease and thus require protection. There is no society in which children survive if deprived of this care provided by older individuals.

Important developments that allow children to progress to the next stage are the eruption of the first permanent molars and completion of growth of the brain (in weight. First molar eruption takes place, on average, between the ages of 5.5 and 6.5 years in most human populations (Jaswal, 1983; Smith, 1992). Recent morphological and mathematical investigation shows that brain growth in weight is complete at a mean age of 7 years (Cabana et al., 1993). At this stage of development the child becomes more capable dentally of processing an adult type diet (Smith, 1991a). Furthermore, nutrient requirements for brain and body growth di-

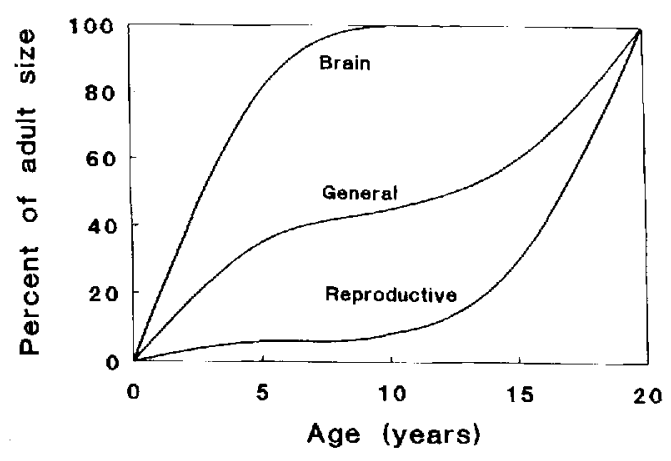

Fig. 4. Growth curves for different body tissues. The "general" curve represents growth in stature or total body weight. The "brain" curve is for total weight and the "reproductive" curve represents the weight of the gonads and primary reproductive organs. (After Scammon, 1930, with brain growth data from Cabana et al., 1993.)

minish, and cognitive capacities mature to new levels of self-sufficiency, e.g., shifting from the preoperational to concrete operational stage in the terminology of Piaget (Piaget and Inhelder, 1969).

The child then progresses to the juvenile stage. Juveniles may be defined as "...prepubertal individuals that are no longer dependent on their mothers (parents) for survival" (Pereira and Altmann, 1985, 
p.236). This definition is derived from ethological research with social mammals, especially nonhuman primates, but applies to the human species as well. Ethnographic research shows that juvenile humans have the physical and cognitive abilities to provide much of their own food and to protect themselves from predation and disease (Weisner, 1987; Blurton Jones, 1993). In girls, the juvenile period ends, on average, at about the age of 10,2 years before it usually ends in boys, the difference reflecting the earlier onset of puberty in girls.

Human adolescence begins with puberty, marked by some visible sign of sexual maturation such as pubic hair. The adolescent stage includes development of the secondary sexual characteristics and the onset of adult patterns of sociosexual and economic behavior. These physical and behavorial changes occur in many species of social mammals. What makes human adolescence different is that during this life stage girls and boys experience a rapid acceleration in the growth of virtually all skeletal tissue, the adolescent growth spurt. The magnitude of this acceleration in growth was calculated by Largo et al. (1978) for a sample of Swiss subjects measured annually between 4 and 18 years of age. In late childhood, statural growth acceleration averaged $-0.47 \mathrm{~cm} / \mathrm{yr} / \mathrm{yr}$, i.e., growth rate was decelerating. From the point of minimal childhood velocity to the peak of the adolescent growth spurt, the acceleration in height averaged $+1.66 \mathrm{~cm} / \mathrm{yr} / \mathrm{yr}$ for boys and $+0.88 \mathrm{~cm} / \mathrm{yr} / \mathrm{yr}$ for girls. At the peak of the growth spurt the average velocity of growth was $9.0 \mathrm{~cm} / \mathrm{yr}$ for boys and $7.1 \mathrm{~cm} / \mathrm{yr}$ for girls.

Other primate species may show a rapid acceleration in soft tissue growth, such as muscle mass in many male monkeys and apes. However, in contrast to humans other primate species either have no acceleration in skeletal growth (Fig. 2) or an increase in growth rate that is very small. In chimpanzees, Watts and Gavan (1982) found that the pubertal increase in the velocity of growth of individual long bones is ". . .usually less than a centimeter" (p. 58) and often less than $5.0 \mathrm{~mm} / \mathrm{yr}$. In contrast, the velocity of human long bone growth may be five times as rapid as that of the ape. Cameron et al. (1982) found that peak adolescent velocities ranged from $1.34 \mathrm{~cm} / \mathrm{yr}$ for the forearm to $2.44 \mathrm{~cm} /$ $\mathrm{yr}$ for the tibia in British boys. Another important ape-human difference in growth is that by the time a chimpanzee begins its modest pubertal acceleration in long bone growth, the animal has already completed $86 \%$ of its skeletal growth. At the onset of the human adolescent growth spurt, by contrast, boys and girls have completed only $77 \%$ of their skeletal growth (Smith, 1993). Clearly, the human pattern of growth following puberty is quantitatively different from the pattern for other primates. The human skeletal growth spurt is unequaled by other species and, when viewed graphically, the growth spurt defines human adolescence (Fig. 3).

Adolescence ends and early adulthood begins with the completion of the growth spurt, the attainment of adult stature, and the achievement of full reproductive maturity (Figs. 3, 4). The latter includes physiological, socioeconomic, and psychobehavioral attributes which all coincide, on average, by about age 19 in women and 21-25 years of age in men (Bogin, 1988, 1993, 1994).

\section{WHEN DID CHILDHOOD AND ADOLESCENCE EVOLVE?}

The stages of the life cycle may be studied directly only for living species. However, there are lines of evidence on the life cycle of extinct species. Such inferences for the hominids are, of course, hypotheses based on comparative anatomy, physiology and ethology, and on archeology. Examples of this methodology are found in Martin (1983) and Harvey et al. (1987) on patterns of brain and body growth in apes, humans, and their ancestors.

Apes have a pattern of brain growth that is rapid before birth and relatively slower after birth. In contrast, humans have rapid brain growth both before and after birth. This difference may be illustrated by comparing ratios of brain weight/total body weight (in grams). At birth, this ratio averages 0.09 for the great apes and 0.12 for human neonates. At adulthood, the ratio averages 0.008 for the great apes and 0.028 for people. In other words, relative to body size human neonatal brain size is 1.33 times larger than that of great apes, but by adulthood the difference is 3.5 times. The rate of human brain growth exceeds that of most other tissues of the body during the first few years after birth (Fig. 4). Martin (1983) and Harvey et al. (1987) also show that human neonates have remarkably large brains (corrected for body size) compared with other primate species. Together, relatively large 
neonatal brain size and the high postnatal growth rate give adult humans the largest encephalization quotient (an allometric scaling of brain to body size) of all higher primates.

Finally, Martin (1983) argues that a "human-like" pattern of brain and body growth becomes necessary once adult hominid brain size reaches about $850 \mathrm{cc}$. This biological marker is based on an analysis of cephalopelvic dimensions of fetuses and their mothers across a wide range of social mammals, including cetaceans, extant primates, and fossil hominids (Martin, 1983). Given the mean rate of postnatal brain growth for living apes, an $850 \mathrm{cc}$ adult brain size may be achieved by all hominoids, including extinct hominids, by lengthening the fetal stage of growth. At brain sizes above $850 \mathrm{cc}$, the size of the pelvic inlet of the fossil hominids, and living people, does not allow for sufficient fetal growth. Thus, a period of rapid postnatal brain growth and slow body growth, the human pattern, is needed to reach adult brain size.

Given this background, Figure 5 represents an attempt to summarize the evolution of the human pattern of growth and development. This figure must be considered as "a work in progress," since only the data for the first and last species (Pan and Homo sapiens) are known with some certainty. AIthough Australopithecus afarensis is a hominid, it shares many anatomical features with nonhominid species including an adult brain size of about $400 \mathrm{cc}$ (Simons, 1989). Analysis of its dentition indicates a rate of dental development indistinguishable from extant apes (Smith, 1991b). Therefore, the chimpanzee and A. aforensis are depicted as sharing the typical tripartite stages of postnatal growth of social mammals, infant, juvenile, and adult. To achieve the larger adult brain size of Australopithecus africanus (442 cc) may have only required an addition to the length of the fetal or, possibly, the infant stage. The rapid expansion of adult brain size during the time of Homo habilis (650$800 \mathrm{cc}$ might have been achieved with expansion of the fetal, infant, and even the juvenile periods. However, further extension of infancy may have placed a severe demographic constraint on $H$. habilis populations. Female primates, including humans, cannot reproduce a new infant successfully if they are still nursing their current infant. Chimpanzees, for example, average 5.5 years be- tween successful births in the wild and young chimpanzees are infants dependent on their mothers for about 5 years (Teleki et al., 1976; Goodall, 1983; Nishida et al., 1990). Actuarial data for wild-living animals indicate that between 35\% (Goodall, 1983) and $38 \%$ (Nishida et al., 1990) of all liveborn chimpanzees survive to their mid-20s. Although this is a significantly greater percentage of survival than for most other species of animals, the chimpanzee is at a reproductive threshold. Goodall (1983) reports that for the period 1965-1980 there were 51 births and 49 deaths in one community of wild chimpanzecs at the Gombe Stream National Park, Tanzania. During a 10-year period at the Mahale Mountains National Park, Tanzania, Nishida et al. (1990, p. 96) observed ". . .74 births, 74 deaths, 14 immigrations, and 13 emigrations. . " in one community. Chimpanzee population growth is, by these data, effectively equal to zero. Extending infancy and birth intervals beyond the chimpanzee range may not have been possible for early hominids such as $H$. habilis.

Insertion of a brief childhood stage into life history could have reduced the reproductive strain. The archeological evidence for intensification of stone tool manufacture and use to scavenge animal carcasses, especially bone marrow (Potts, 1988), may be interpreted as a strategy to feed children. Such scavenging may have been needed to provide essential amino acids, some minerals, and especially fat (dense source of energy) that children require for growth of the brain and body (Leonard and Robertson, 1992).

Brain size increased further during the time of $H$. erectus. The earliest adult specimens have brain sizes of $850-900 \mathrm{cc}$. This places $H$. erectus at Martin's (1983) adult brain size marker, and may justify an expansion of the childhood period to provide the high-quality foods needed for the rapid, human-like, pattern of brain growth. Note also that infancy is depicted as decreasing in duration as childhood expands. Hypothetically, this gives $H$. erectus a reproductive advantage over other hominoids. With this advantage it is easier to understand why population size and the geographic range of $H$. erectus expand beyond that of all prior hominids.

There is evidence that early $H$. erectus did not have an adolescent growth spurt. Smith (1993) analyzed the skeleton and dentition 


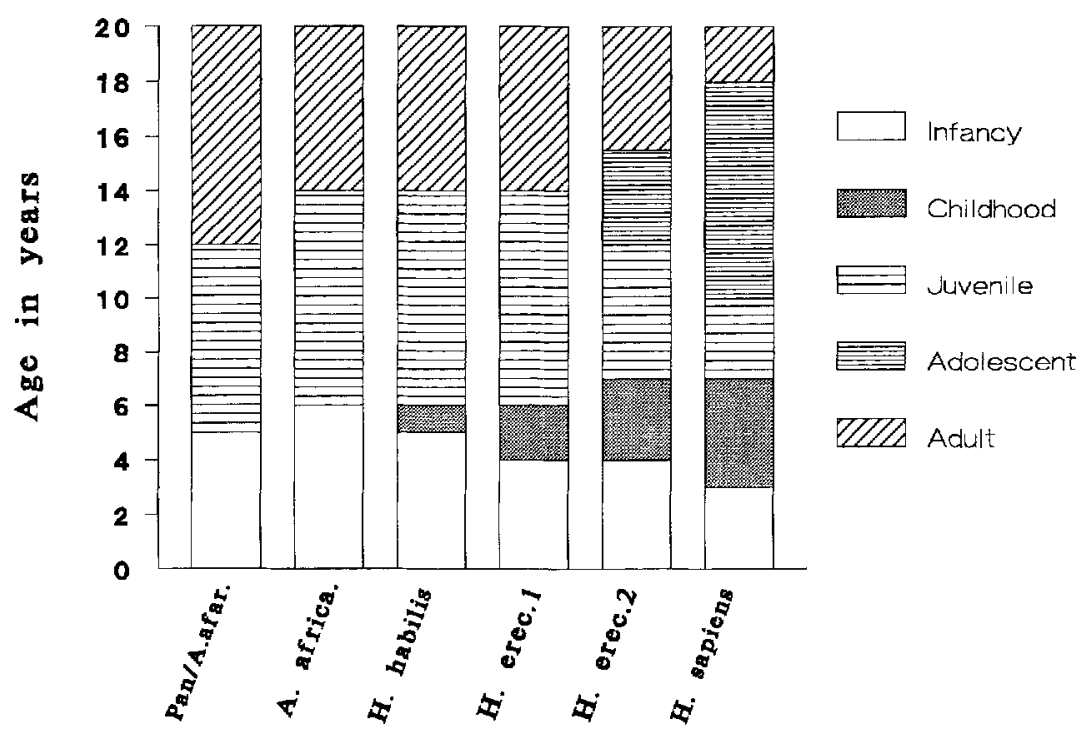

Fig. 5. The evolution of hominid life history during the first 20 ycars of life, Abbreviated nomenclature as follows: A. afar, Australopithecus afarensis; A. africa, Australopithecus africanus; $\mathrm{H}$. habilis, Homo habilis; H. erec. 1, early Homo erectus; H. erec. 2, late Homo erectus; H. sapiens, Homo sapiens.

of the fossil specimen KMN-WT 15000 (the "Turkana boy"), a 1.6 million year old (early) H. erectus skeleton. Using data for skeletal growth and maturation of living apes and humans, Smith (1993) developed a model of $H$. erectus skeletal growth and maturation, in which a $H$. erectus youth of 14.5 years would be entering young adulthood and was comparable in maturation to an 11.4-yearold chimpanzee and an 18 to 21-year-old modern human. The Turkana boy, who was probably less than 11 years of age at death, was "too advanced" in skeletal development to have followed a modern human pattern of growth. Smith (1993) concludes that, "I the 'Turkana boy's'] dental age, skeletal age, and body size are quite consistent with the idea that the adolescent growth spurt had not yet evolved in Homo erectus. . .[but]. . the unique skeleton of KMN-WT 15000 stands at a point near the very beginning. . of the evolution of human life history" ( $p p$. 218-219).

Late $H$. erectus, with adult brain sizes up to $1,100 \mathrm{cc}$, is depicted in Figure 5 with further expansion of childhood and the insertion of the adolescent stage. Along with bigger brains, late $H$. erectus shows increased complexity of technology (tools, fire, and shelter) and social organization that were likely to require an adolescent stage of development in order to become a successful adult member of society (see below for explanation). The transition to archaic and finally modern $H$. sapiens expands the childhood and adolescent stages to their current dimensions.

\section{WHY DO NEW LIFE STAGES EVOLVE?}

Bonner (1965) has developed the idea that the stages of the life cycle of an individual organism, a colony, or a society are "...the basic unit of natural selection." Bonner's focus on life cycle stages follows in the tradition of many of the 19th century embryologists who proposed that speciation is often achieved by altering rates of growth of existing life stages and by adding or deleting stages. Bonner shows that the presence of a stage and its duration in the life cycle relate to such basic adaptations as locomotion, reproductive rates, and food acquisition. From this theoretical perspective, it is profitable to view the cvolution of human childhood and adolescence as adaptations for both feeding and reproduction.

Figure 6 depicts several hominoid developmental landmarks. In comparison with living apes, people experience developmental delays in eruption of the first perma- 


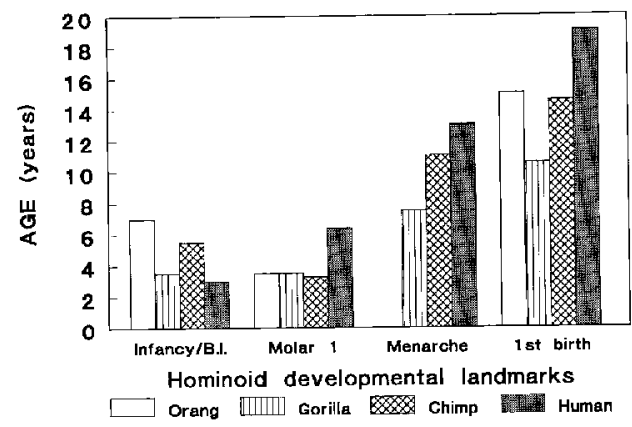

Fig. 6. Hominoid developmental landmarks. Data hased on observations of wild-living individuals, or for humans, healthy individuals from various cultures. Species abbreviations are: Orang, Pongo pygmaeus; Gorilla, Gorilla gorilla; Chimp, Pan troglodytes; Human, Homo sapiens. Developmental landmarks are: Infancy/B.I., period of dependency on mother for survival, usually coincident with mean age at weaning and/or a new birth (B.I. = birth interval); Molar 1, mean age at eruption of lirst permanent molar; Menarche, mean age at first estrus/menstrual bleeding; 1st birth, mean age of females at first offspring delivery. (Data from Bogin, 1988, 1994); Galdikas and Wood, 1990; Nishida et al., 1990; Smith, 1992; Watts and Pusey, 1993.)

nent molar, age at menarche, and age at first birth. However, people have a shorter infancy and shorter birth interval, which in apes and traditional human societies are virtually coincident. The net result is that humans have the potential for greater lifetime fertility than any ape, but also have the problem of caring for children, who are dependent on older individuals for feeding and protection.

The peoples of traditional societies solved the problem of child care by spreading the responsibility among many individuals. The child must be given foods that are specially chosen and prepared, and these may be provided by older juveniles, adolescents, or adults. In Hadza society (hunters and gatherers), for example, grandmothers and great-aunts supply a significant amount of food and care to children (Blurton Jones, 1993). In Agta society (Philippine huntergatherers), women hunt large game animals but still retain primary responsibility for child care. They accomplish this by living in extended family groups, two or three brothers and sisters, their spouses, children and parents, and by sharing in child care (Estioko-Griffin, 1986). Among the Maya of Guatemala (horticulturists and agricultural- ists), many people live together in extended family compounds. Women of all ages work together in food preparation, manufacture of clothing, and child care (Bogin, fieldwork notes, 1988-1993). Juvenile girls associate with these working groups and provide much of the direct care and fecding of children, but always under the guidance of adolescents and adults. In some societies fathers provide significant child care, including the Agta, who take their children on hunting trips, and the Aka Pygmies, a hunting-gathering people of central Africa (Hewlitt, 1991). Summarizing the data from many human societies, Lancaster and Lancaster (1983) refer to this type of child care and feeding as "the hominid adaptation," for no other primate or mammal does all of this. The "bottom line," in a biological sense, is that the evolution of human childhood frees the mother from the demands of nursing and the inhibition of ovulation related to continuous nursing. This, in turn, decreases the interbirth interval and increases reproductive fitness.

An adolescent stage of human growth may have evolved to provide the time needed to practice complex social skills needed to be an effective parent. The evolution of childhood afforded hominid females the opportunity to give birth at shorter intervals, but producing offspring is only a small part of reproductive fitness. Rearing the young to their own reproductive maturity is a more sure indicator of success. Studies of yellow baboons, toque macaques, and chimpanzees show that between $50 \%$ and $60 \%$ of first-born offspring die in infancy. By contrast, in hunter-gatherer human societies, between $44 \%$ (!Kung) and $39 \%$ (Hazda) of offspring die in infancy. Studies of wild baboons by Altmann (1980) show that, while the infant mortality rate for the first-born is $50 \%$, mortality for the second-born drops to $38 \%$, and for third- and fourth-born reaches only $25 \%$. The difference in infant survival is, in part, due to experience and knowledge gained by the mother with each subsequent birth. Such maternal information is generally mastered by human women during adolescence, which gives them a reproductive edge. The initial human advantage may seem small, but it means that up to 21 more people than baboons or chimpanzees survive out of every 100 firstborn, more than enough over the vast course of evolutionary time to make the evolution 
of human adolescence an overwhelmingly beneficial adaptation.

Adolescent girls gain knowledge of sexuality, reproduction, and infant care because they look mature sexually and are treated as such, several years before they actually become fertile. The adolescent growth spurt serves as a signal of maturation. Early in the spurt, before peak height velocity is reached, girls develop pubic hair and fat deposits on breasts, buttocks, and thighs. In essence, they appear to be maturing sexually. About a year after peak height velocity, girls experience menarche, an unambiguous external signal of internal reproductive system development. However, most girls experience 1-3 years of anovulatory menstrual cycles following menarche. Fertility is not achieved until near the end of the adolescent growth stage. Nevertheless, the dramatic changes of adolescence stimulate both the girls and adults around them to participate in adult social, sexual, and economic behaviors. For adolescent girls, this participation is "risk free" in terms of pregnancy, but does allow them to learn and practice behaviors that lead to increased reproductive fitness in later life. For this very fundamental biological reason, girls should wait up to a decade from the time of menarche to reach full reproductive maturity. Cross-cultural behavior verifies this conclusion, since age at first marriage and childbirth clusters around 19 years for women from such diverse cultures as the Kikuyu of Kenya, Mayans of Guatemala, Copper Eskimo of Canada, and both the Colonial and contemporary United States.

The adolescent development of boys is quite different from girls. Boys become fertile well before they assume adult size and the physical characteristies of men. Analysis of urine samples from boys age 11-16 years of age shows that they begin producing sperm at a median age of 13.4 years (Muller et al., 1989). Yet, the cross-cultural evidence is that few boys successfully father children until they are into their third decade of life (Bogin, 1993, 1994). In the United States, for example, only $3.1 \%$ of live-born infants in 1990 were fathered by men under 20 years of age (National Center of Health Statistics, 1994). Worthman (1986) reports that among the traditional Kikuyu of East Africa, men do not marry and become fathers until about age 25 years, although they become sexual active following their own circumcision rite at around 18 years of age.
One explanation for the lag between sperm production and fatherhood may be that the sperm of younger adolescents are not motile, or do not have the endurance to swim to an egg in the fallopian tubes. A more probable reason is that the average boy of 13.4 years is only beginning his adolescent growth spurt. In terms of physical appearance, physiological status, psychosocial development, and economic productivity, he is still more of a child than an adult. Few women, and more importantly from a crosscultural perspective, few prospective inlaws, view a teenage boy as a biologically, economically, and socially viable husband and father.

The delay between sperm production and reproductive maturity is not wasted time in either a biological or social sense. The obvious and the subtle psycho-physiological effects of testosterone and other androgen hormones that are released following gonadal maturation may "prime" boys to be receptive to their future roles as men. Alternatively, it is possible that physical changes stimulated by the endocrines provide a social stimulus toward adult behaviors (Halpern et al., 1993). Whatever the case, early in adolescence sociosexual feelings intensify, including guilt, anxiety, pleasure, and pride (Higham, 1980; Petersen and Taylor, 1980). At the same time, boys become more interested in adult activities, adjust their attitude to parental figures, and think and act more independently. However, and this is where the survival advantage may lie, they still look like boys. Because their adolescent growth spurt occurs late in sexual development, young males can practice behaving like adults before they are actually perceived as adults. The sociosexual antics of young adolescent boys are often considered to be more humorous than serious. Yet, they provide the experience to fine tune sexual and social roles before either their lives, or those of their offspring, depend on them. For example, competition between men for women favors the older, more experienced man. Since such competition may be fatal, the child-like appearance of the immature, but hormonally and socially primed, adolescent male may be life-saving as well as educational.

\section{THE VALUABLE GRANDMOTHER, OR COULD MENOPAUSE EVOLVE?}

In addition to childhood and adolescence, there is another unusual aspect of human life history, menopause. One generally ac- 
cepted definition of menopause is "...the sudden or gradual cessation of the menstrual cycle subsequent to the loss of ovarian function. ..."(Timiras, 1972, p. 531). The process of menopause is closely associated with the adult female post-reproductive stage of life, but menopause is distinct from the postreproductive stage. Reproduction usually ends before menopause. In traditional socicties, such as the !Kung (Howell, 1979), the Dogon of Mali (B. Strassman, personal communication), and the rural-living Maya of Guatemala (Minesterio de Salud Publica, 1989 ), women rarely give birth after 40 years of age and almost never give birth after 44 years. Menopause, however, occurs after age 45 in these three societies. In the United States, from 1960 to 1990 , data for all births show that women $45-49$ years gave birth to fewer than 1 out of 1,000 live born infants. In contrast, there were $16.1 / 1,000$ live births to women aged 40-44 years (National Center for Health Statistics, 1994). Similar patterns of birth are found for the Old Order Amish, a high fertility, noncontracepting population residing primarily in the states of Pennsylvania, Ohio, and Indiana. Amish women aged 45-49 years born before 1918 gave birth to an average of 13 infants per 1,000 married women, while women between 40 and 44 years of age gave birth to an average of 118 infants per 1,000 married women (Ericksen et al., 1979). Thus, even in the United States of 1960-1990, with modern health care, good nutrition, and low levels of hard physical labor, and even among social groups attempting to maximize lifetime fertility, women rarely give birth after age 45 years. As for the!Kung, Dogon, and Maya, menopause occurs well after this fertility decline, at a mean age of 49 years for United States women (Pavelka and Fedigan, 1991). After age 50, births are so rare that they are not reported in the data of the National Center for Health Statistics or for the Amish.

These ages for the onset of human female post-reproductive life vs. the ages for menopause are given for two reasons. The first is that some scholars incorrectly equate menopause with the beginning of the post-reproductive stage. The second reason is that menopause and a significant period of life after menopause are claimed by some scholars to be uniquely human characteristics. Other scholars assert that menopause is a shared trait with other mammals.

In a review of menopause from a comparative primate and evolutionary perspective,
Pavelka and Fedigan (1991) found that menopause is a virtually universal human female characteristic and that menopause occurs at approximately 50 years of age in all human populations. In contrast, Pavelka and Fedigan note that wild-living nonhuman primate females do not share the universality of human menopause, and human males have no comparable life history event. In a review of data for all mammals, Austad (1994, p. 255) finds that no wild-living species except, possibly, pilot whales, "... are known to commonly exhibit reproductive cessation..." Female primates studied in captivity, including langurs, baboons, rhesus macaques, pigtailed macaques, and chimpanzees, usually continue estrus cycling until death, although there are fertility declines with age (Fedigan and Pavelka, 1994). These declines are best interpreted as a normal part of aging. The review of Fedigan and Pavelka (1994) finds that one captive bonobo over 40 years old (Gould et al., 1981) and one captive pigtail macaque over 20 years old (Graham et al,, 1979) ceased estrus cycling. These two very old animals showed changes in hormonal profiles similar to human menopause and on autopsy had depleted all oocytes. Finally, Pavelka and Fedigan (1991) point out that, in contrast to the senescent decline in fertility of other female primates, the human female reproductive system is abruptly "shut down" well before other systems of the body which usually experience a gradually decline toward senescence. Moreover, women may live for decades after oocyte depletion (menopause), but other female primates die before or just after oocyte depletion.

Figure 7 illustrates the timing of the onset of the adult female post-reproductive stage and menopause in the context of the evolution of human life history. Again, as for Figure 5, the data for fossil hominids are speculative and extrapolated, in part, from evidence provided by extant chimpanzees and human beings. Nishida et al. (1990) report that wild-living female chimpanzees give birth to their last offsprng in their late 30 s or early $40 \mathrm{~s}$. They may then experience between $2.5-9.5$ years (median $=3.9$ years) of post-reproductive life, but most of these females continue estrus cycles until death. Based on these findings, a median age of 40 years for the onset of the chimpanzee postreproductive stage is used for Figure 7 . At the other end of the range are human females. The data available from industrial- 


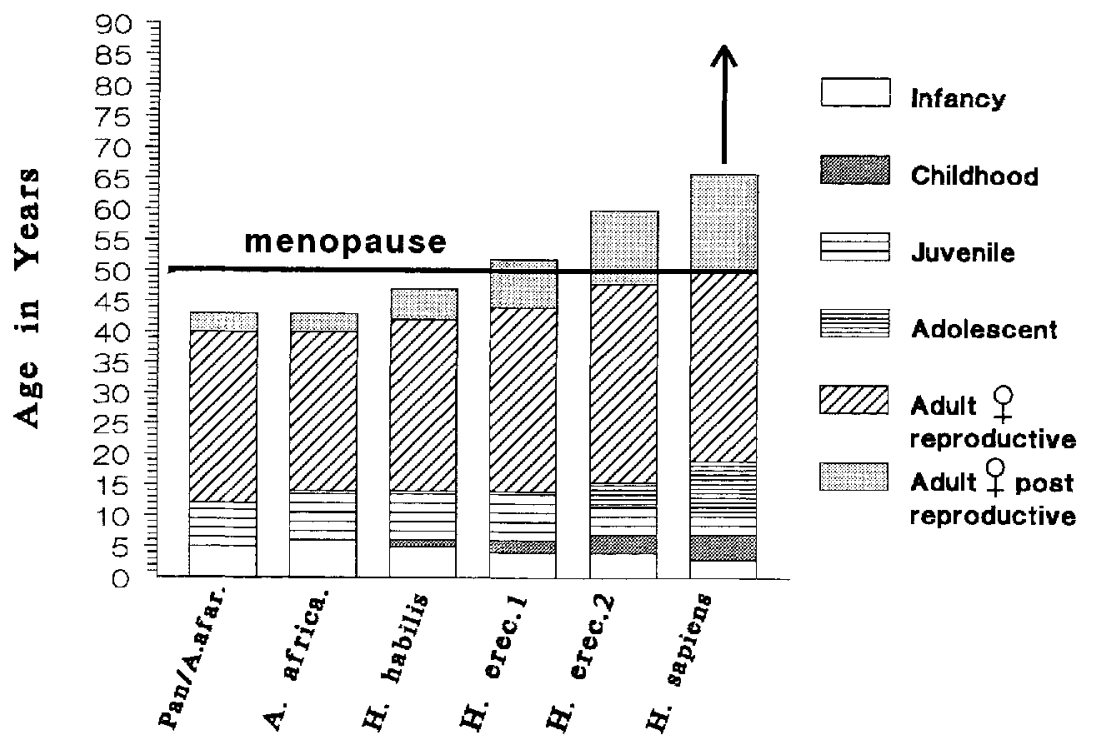

Fig. 7. The evolution of human female life history emphasizing the post-reproductive stage. Life expectancy estimated by the formula of Smith (1991b). The arrow above the $H$. sapiens column represents Sacher's (1975) estimate of maximum longevity to 89 years. Increased human longevity extends the post-reproductive stage, not earlier stages of the life cycle. Abbreviations as in Figure 5 .

ized nations and a few traditional societies provide mean ages of menopause from 48 to 51 years (Timiras, 1972; Pavelka and Fedigan, 1991), and as noted, virtually no women over age 50 give birth. Accordingly, 50 years is used as a representative age for menopause and also the maximum age for onset of the human female post-reproductive stage. It is also proposed that 50 years is the effective upper limit for the age at menopause (oocyte depletion) of hominoids in general, based upon the human condition and the one known chimpanzee (bonobo) to experience menopause.

The estimates of life expectancy depicted in Figure 7 are based on regression formulae developed by Smith (1991b). The formulae predict life expectancy using data for body and brain weight. The estimates for the chimpanzee ( 43 years) and for $H$. sapiens (66 years) accord well with data for wild chimpanzees (the maximum lifespan of captive chimpanzees is 50 years) and traditional human societies (e.g., Nishida et al., 1990 for chimps; Neel and Weiss, 1970; Howell, 1979 for humans). The $H$. sapiens column also includes an extension of predicted life expectancy to 89 years. This estimate is based on the formula of Sacher (1975) for maximum longevity and is being approached by populations of the most highly industrialized nations. Smith's (1991b) formula is also used for prediction of life expectancy for fossil species. The predictions are hypothetical and are based on the best available estimates of body and brain weight.

Age at onset of the post-reproductive stage for female fossil hominids is based on an extrapolation between known mean ages for chimpanzees and humans. A linear interpolation was used to calculate the ages for the fossils. A curvilinear fit, a step function, or some other discontinuous function may better represent the true nature of change in the age of onset of a post-reproductive life stage. Empirical research is needed to determine the best model. It is possible that empirical evidence for evolution of the post-reproductive stage for women will be recoverable from the fossil record because the hormonal changes associated with menopause have profound effects on the bone mass and histology of tubular bones. According to Garn (1970), there is a gain of bone mass and an increase in deposition on the endosteal surface of tubular bones during the "steroid mediation phase" of life, e.g., during adolescence and reproductive adult- 


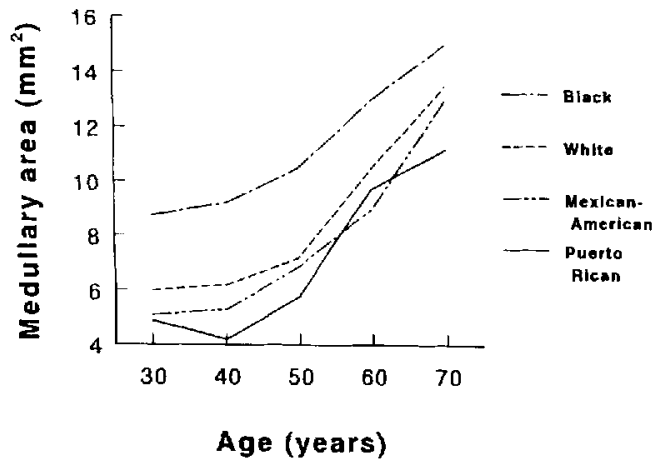

Fig. 8. Age changes in medullary area for several nationally representative samples of populations of women residing in the United States. Medullary area increases after the third decade of life in all populations and the rate of bone loss increases after age 50 , i.e., at the time of menopause (data kindly provided by Prof. S.M. Garn).

hood. Moreover, the endosteal gain is greater in women than in men. By the fifth decade of life, the apposition of endosteal bone stops and resorption begins. Data for women of European, African, Mexican, and Puerto Rican origin living in the United States are illustrated in Figure 8. Although there are apparent differences in the absolute amount of bone remodeling, the process occurs in all populations thus far investigated.

Age changes of this sort can be detected in both archeological samples, e.g., archaic/ pre-contact Native American burials (Carlson et al., 1976; Ruff, 1991) and paleontological collections (Ruff et al., 1993; Trinkhaus et al., 1994). Based upon these predictable age and sex changes in bone remodeling, a post-reproductive life history stage should be detectable in the fossil record.

Recovering these data may help settle the question of why human women have considerable longevity beyond menopause. Basically, there are two models for the evolution of menopause and a post-reproductive life stage. One model posits that a post-reproductive life stage could evolve if there are major risks to reproduction for an older female and if the older female can benefit her younger kin. The extraordinary duration of the human female post-reproductive life stage correlates with cross-cultural ethnographic research showing the crucial importance of grandparents as repositories of ecological and cultural information, and the value of grandmothers for child care. Hamilton (1966) formalized the "grandmother model" into a hypothesis based on models of kin selection theory, but until recently the hypothesis was not tested scientifically. Nishida et al. (1990) demonstrate that a few wild chimpanzee females have a post-reproductive stage, but the kin selection hypothesis does not correlate well with chimpanzee behavior; ". . the evolutionary advantage of menopause [sic] in female chimpanzees is puzzling, since they rarely, if ever, care for younger relatives. . aged females typically live a lonely life. .." (p. 95). In a recent attempt to test the kin selection hypothesis with human data, Hill and Hurtado (1991) were unable to show that it would ever be advantageous to stop reproducing altogether. The authors used several hypothetical models that covered the range of reasonable estimates of maternal cost vs. grandmother benefits. The predictions were also tested against objective ethnographic data derived from work with the Ache, hunter-gatherers of South America. The Ache data show that offspring with grandmothers survive at somewhat higher rates than those without grandmothers, but the effect is not nearly enough to account for menopause. In a recent review of the Ache data and other cases derived from huntinggathering and agricultural societies, Austad (1994, p. 255) finds no evidence, " . . that humans can assist their descendants sufficiently to offset the evolutionary cost of ceasing reproduction."

The second model for menopause may be termed the "pleiotropy hypothesis." In now classic works on the biology of senescence, Medawar (1952) and Williams (1957) argued that aging is ". . due to an accumulation of harmful age specific genes...lor]... pleiotropic genes which have good effects early in life, but have bad effects later. ." (Kirkwood and Holliday, 1986, p. 371). Kirkwood (1977), Charlesworth (1980), and others refined this hypothesis further in terms of a general theory of aging. Pavelka and Fedigan (1991) apply this line of reasoning to menopause. According to their application of the "pleiotropy hypothesis," menopause is a secondary consequence of the female mammalian reproduction system. This system has a physiological limit of about 50 years because of limitations on egg supply or on the maintence of healthy eggs. Female mammals produce their egg supply during prena- 
tal development, but suspend the meiotic division of the eggs in anaphase. Approximately 1 million primary oocytes may be produced, but most degenerate, so that in the case of female humans only about 400 are available for reproduction. During human adolescence and adulthood, the remaining primary oocytes complete their maturation and are released in series during menstrual cycles. By about age 50, all of these eggs are depleted. If the woman lives beyond the age of depletion she will experience menopause. The physiological connection between oocyte depletion and the hormonal changes of menopause has yet to be elucidated. However, the pleiotropy hypothesis does account for the observation that few female mammals reproduce after 40-50 years of age, even though some species, such as humans, may live another 25 or 50 years.

Menopause and the post-reproductive life stage of women are, then, an inevitable consequence of the age-limited reproductive capacities of all female mammals. However, even if menopause is a pleiotropic consequence of mammalian reproduction, grandmotherhood may still be an important biological and sociocultural stage in the human female life cycle. The universality of human menopause makes it possible to develop biocultural models to support a combination of the pleiotropy and "grandmother" hypotheses. Basically, if a 50-year age barrier exists to female fertility, then the only reproductive strategy open to women living past that age is to provide increasing amounts of aid to their children and their grandchildren. This strategy is compatible with Hamilton's kin selection hypothesis. Kin selection alone, however, cannot account for the evolution of menopause or grandmotherhood. A biocultural model for the evolution of grandmotherhood that combines the pleiotropy and kin selection hypotheses is proposed. In favor of the biocultural model is the ethnographic evidence showing that significant numbers of women in virtually every society, traditional or industrial, live for many years after menopause. Moreover, the ethnographic evidence also shows that grandmothers and other post-reproductive women are beneficial to the survival of children in many human societies.

Little comparative mammalian data on the value of grandmotherhood exist because the females of wild-living species of primates and other social mammals only rarely sur- vive to a post-reproductive stage. There are some exceptional species, e.g., hyenas. Grandmother caretaking occurs in this species, including the nursing of grandoffspring. Indeed, when both are still fertile, mother and daughter hyenas take turns nursing each other's young (Mills, 1990). It is not known if this practice is widespread in other social carnivores. Nevertheless, the point is that when females do survive regularly past the reproductive stage of life, the basis for affiliative behaviors, including some grandmother interaction and care of young, exists in social mammals.

During hominid evolution, a post-reproductive life stage of significant duration and menopause became commonplace as life expectancy increased beyond 50 years. It is not known when this occurred, but needs to be investigated. The regular occurrence of a post-reproductive female hominid life stage would select for females (and males?) of the species to develop biocultural strategies to take greatest advantage of this situation. Viewed in this context, human grandmotherhood may be added to human childhood and adolescence as distinctive stages of the human life cycle.

\section{LITERATURE CITED}

Altmann $J$ (1980) Baboon Mothers and Infants. Cambridge, MA: Harvard University Press.

Austad SN (1994) Menopause: An evolutionary perspeclive. Exp. Gerontol. 29:255-263.

Bertalanffy L von (1960) Principles and theory of growth. In WN Nowinski (ed.): Fundamental Aspects of Normal and Malignant Growth. Amsterdam: Elsevier, pp. 137-259.

Blurton Jones NG (1993) The lives of hunter-gather children: Effects of parental behavior and parental reproductive strategy. In ME Periera, and LA Fairbanks (eds.): Juvenilc Primates. Oxford: Oxford University Press, pp. 309-326.

Bogin B (1988) Patterns of Human Growth. New York: Cambridge University Press.

Bogin B (1990) The evolution of human childhood. Bioscience. 40:16-25.

Bogin B (1993) Why must I be a teenager at all? New Sci. 137:34-38.

Bogin B (1994) Adolescence in evolutionary perspective. Acta Paediatr. (Suppl.) 406:29-35.

Bonner JT (1965) Size and Cycle. Princeton, N.J: Princeton University Press.

Cabana T, Jolicoeur P, and Michaud J (1993) Prenatal and pastnatal growth and allometry of stature, head circumference, and brain weight in Québec children. Am. J. Hum. Biol, 5:93-99.

Cameron N, Tanner JM, and Whitehouse RH (1982) A longitudinal analysis of the growth of limb segments in adolescence. Ann. Hum. Biol. 9:211-220.

Carlson DS, Armelagos GJ, and Van Gerven DP (1976) Patterns of age-related cortical bone loss (osteoporo- 
sis) within the femoral diaphysis. Hum. Biol 48: 295-314.

Charlesworth B (1980) Evolution in Age-Structured Populations. Cambridge: Cambridge University Press.

Coclho AM (1985) Baboon dimorphism: Growth in weight, length, and adiposity from birth to 8 years of age. In ES Watls (ed.): Nonhuman Primate Models for Human Growth. New York: Alan R. Liss, pp. 125-159.

Dettwyler KA (1994) A time to wean: The hominid blueprint for the natural age of weaning in modern human populations. Am. J. Phys. Anthropol. (Suppl.) 18:80 (abstract).

Ericksen JA, Ericksen EP, IIostctler JA, and Huntington GE (1979) Fertility patterns and trends among the Old Order Amish. Popul. Stud. 33:255-276.

Estioko-Griffin A (1986) Daughters of the forest. Natural History 95:36-43.

Fedigan LM and Pavelka MSM (1994) The physical anthropology of menopause. In A Herring and MSM Pavelka (eds): Strength in Ijiversity. Toronto: Canadian Schulars Press, pp. 103-126.

Galdikas BM, and Wood JW (1990) Birth spacing patterns in humans and apes. Am. J. Phys. Anthropol. 83:185-191.

Garn SM (1970) The Earlier Gain and Later Loss of Cortical Bone in Nutritional Perspective. Springfield, IL: Charles C. Thomas.

Goodall J (1983) Population dynamics during a 15 year period in one community of free-living chimpanzees in the Gombe National Park, Tanzania. Zeit. Tierpsychol. 61:1-60.

Gould KG, Flint M, and Graham CE (1981) Chimpanzee reproductive senesence: A possible model for the evolution of the menopause. Maturitas 3:157-166.

Graham CE, Kling OR, and Steiner RA (1979) Reproductive senescence in female nonhuman primates. In D. Bowden (ed.): Aging in Nonhuman Primates. New York: Van Nostrand Reinhold, pp. 183-209.

Halpern CT, Ldry RJ, Campbell B, and Suchinddran $\mathrm{C}$ (1993): Testosterone and pubertal development as predictors of sexual activity: A panel analysis of adolescent males. Psychosom. Med. 55:436-447.

Hamilton W (1966) The moulding of senescence by natural selection. J. Theor. Biol. 12:12-45.

Ilarvey $\mathrm{PH}$, Martin RD, and Clutton-Brock TH (1987) Life histories in comparative perspective. In $\mathrm{BB}$ Smuts, DL Chency, RM Seyfarth, RW Wrangham, and TT Struhsaker (eds.): Primate Societies. Chicago: University of Chicago Press, pp. 181-196.

Hewlitt BS (1991) Intimate Fathers: The Nature and Context of Aka Pygmy Paternal Care. Ann Arbor, MI: University of Michigan Press.

Higham f' (1980) Variations in adolescent psychohormonal development. In J Adelson (ed.): Handbook of Adolescent Psychology. New York: Wiley, pp. 472-494.

Hill K, and Hurtado AR (1991): The evolution of premature reproductive senescence and menopause in human females: An evaluation of the "Grandmother $\mathrm{Hy}$ pothesis." Hum. Nature 2:313-350.

Howell N (1979) Demography of the Dobe !Kung. New York: Academic Press.

Jaswal S (1983) Age and sequence of permanent tooth emergence among Khasis. Am. J. Phys. Anthropol. 62: $177-186$.

Kirkwood TBL (1977) Evolution of aging. Nature 270: 301-304.

Kirkwood TBL, and Holliday R (1986) Selection for opti- mal accuracy and the evolution of aging. In TBL Kirkwood, RF Rosenberger, and DJ Galas (eds.): Accuracy in Molecular Processes. New York: Chapman and Hall, pp. 363-379.

Lancaster JB, and Lancaster CS (1983) Parental investment: The hominid adaptation. In DJ Ortner (ed.) How Humans Adapt. Washington, DC: Smithsonian Institution Press, pp. 33-65.

Largo RH, Gasser Th, Prader A, Stutzle W, and Huber PJ (1978) Analysis of the adolescent growth spurt using smonthing spline functions. Ann. Hum. Biol. 5:421434.

Leonard WR, and Robertson ML (1992) Nutritional requirements and human evolution: A bivenergetics model. Am. J. Hum. Biol. 4:179-195.

Martin RD (1983) Human brain evolution in an ecological context. New York: American Museum of Natural History.

Medawar PB (1952) An Unsolved Problem in Biology. London: HK Lewis.

Mills MGL (1990) Kalahari Hyenas. London: Unwin Hyman

Ministerio de Salud Publica (1989) Encuesta Naciona de Salud Materno Infantil 1987. Guatemala City: Minesterio de Salud Publica.

Muller J, Nielsen CT, and Skakkebaek NE (1989) Testicular maturation and pubertal growth and development in normal boys. In JM Tanner and MA Preece (eds.): The Physiology of Human Growth. Cambridge: Cambridge University Press, pp. 201-207.

National Center for Health Statistics (1994) Vital Statistics of the United States, Vol. 1, Natality. Washington, DC: Public Health Service.

Neel JV, and Weiss K (1975) The genetic structure of a tribal pnpulation, the Yanomamo Indians. Biodemographic studies XII. Am. J. Phys. Anthropol. 42:25-52.

Nishida T, Takasaki $H$, and Takahata $Y(1990)$ Demography and reproductive profiles. In T Nishida (ed.): The Chimpanzees of the Mahale Mountains: Sexual and Life History Strategies. Tokyo: University of Tokyo Press, pp. 63-97.

Pavelka MSM, and Fedigan LM (1991) Menopause: A comparative life history perspective. Yrbk. Phys. Anthropol. 34:13-38.

Pereira ME, and Altmann J (1985) Development of social behavior in frce-living nonhuman primates. In ES Watts (ed): Nonhuman Primate Models for Human Growth and Development. New York: Alan R. Liss, pp. 217-309.

Petersen AC, and Taylor B (1980) The biological approach to adolescence: Biological change and psychological adaptation. In J Adelson (ed.): Handbook of Adolescent Psychology. New York: Wiley, pp. 117-155.

Piaget $J$, and Inheider B (1969): The Psychology of the Child. New York: Basic Books.

Potts R (1988) Early Hominid Activities at Olduvai. New York: Aldine de Gruyter.

Prader A (1984) Biomedical and endocrinological aspects of normal growth and development. In J Borms, $R$ Hauspie, A Sand, C Susanne, and M Hebbelinck (cds.): Human Growth and Development. New York: Plenum, pp. 1-22.

Ruff CB (1991) Aging and Osteoporosis in Native Americans from Pecos Pueblo, New Mexico: Behavioral and Biomechanical Effects. New York: Garland.

Ruff CB, Trinkhaus E, Walker A, and Larsen CS (1993) Postcranial robusticity in Homo. I: Temporal trends 
and mechanical interpretation. Am. J. Phys, Anthropol. $91: 21-53$.

Sacher GA (1975) Maturation and longevity in relation to cranial capacity in hominid cvolution. In R Tuttle (ed.): Primate Functional Morphology and Evolution. The Hague: Mouton, pp. 417-441.

Scammon RE (1930) The measurement of the body in childhood. In JA Harris, CM Jackson, DG Paterson, and RE Scammon (eds.): The Measurement of Man. Minneapolis: University of Minnesota Press, pp. $173-215$.

Shea BT (1990) Dynamic morphology: Growth, life history, and ecology in primate evolution. In CJ DeRousseau (ed.): Primate Life History and Evolution. New York: Wiley-Liss, pp. 325-352.

Simons EL (1989) Human origins. Science 245: 1343-1350.

Smith BH (1991a) Agc at weaning approximates age of emergence of the first permanent molar in non-human primates. Am. J. Phys. Anthropol. (Suppl.) 12:163164 (abstract).

Smith BH (1991b) J)ental development and the evolution of life history in Hominidae. Am. J. Phys. Anthropol. 86:157-174.

Smith BH(1992) Life history and the evolution of human maturation. Evol. Anthropol. 1:134-142.

Smith BH (1993) Physiological age of KMN-WT 15000. In AC Walker and RF Leakey (eds.): The Nariokotome Homo ereclus Skeleton. Cambridge, MA: Belknap Press, pp. 195-220.

Tanner JM (1962) Growth at Adolescence. 2nd edition. Oxford: Blackwell Scientific Publications.
Teleki GE, Hunt E, and Pfifferling JH (1976) Demographic observations (1963-1973) on the chimpanzees of the Gombe National Park, Tanzania. J. Hum. Evol. 5:559-598.

Timiras PS (1972) Developmental Physiology and Aging. MacMillan: New York.

Trinkaus E, Churchill SE, and Ruff CB (1994) Pustcranial robusticity in Homo. II: Humeral bilateral asymmetry and bone plasticity. Am. J. Phys. Anthropol. 93:1-34.

Watts DP, and Pusey AE (1993) Behavior of juvenile and adolescent great apes. In ME Pereira and LA Fairbanks (eds.): Juvenile Primates. Oxford: Oxford University Press, pp. 148-170.

Watts ES, and Gavan JA (1982) Postnatal growth of nonhuman primates: The problem of the adolesecnt spurt. Hum. Biol. 54:53-70.

Weisner TS (1987) Socialization for parenthood in sibling caretaking societies. In JB Lancaster, J Altmann, AS Rossi, and LR Sherrod (eds.): Parenting Across the Life Span: Biosocial Dimensions. New York: Aldine de Gruyter, pp. 237-270.

Williams GC (1957) Pleiotropy, natural selection and the evolution of senescence. Evolution 11:398-411.

Worthman C (1986) Developmental dyssynchrony as normative experience: Kikuyu adolescents. In J Lancaster and BA Hamburg (eds.): School-age Pregnancy and Parenthood: Biosocial Dimensions. New York: Aldine de Gruyter, pp. 95-112. 